\title{
Green Synthesis of Silver Nanoparticles from Several NTFP Plants
}

\author{
Somnath BHOWMIK ${ }^{1 *}$, Badal Kumar DATTA ${ }^{2}$, Ajay Krishna SAHA ${ }^{3}$, \\ Pradyut CHAKMA ${ }^{2}$, Narayan Chandra MANDAL ${ }^{4}$ \\ ${ }^{1}$ Rabindranaththakur Mahavidyalaya, Bishalgarh, Department of Botany, Tripura, 799102, India; sombhowmik@gmail.com (*correspondingauthor) \\ ${ }^{2}$ Tripura University, Plant Taxonomy and Biodiversity Laboratory, Department of Botany, \\ Suryamaninagar, 799022, India \\ ${ }^{3}$ Tripura University, Plant Pathology and Mycology Laboratory, Department of Botany, Suryamaninagar, 799022, India \\ ${ }^{4}$ Visva-Bharati University, Department of Botany, Microbiology and Mycopathology Laboratory, Santiniketan Birbhum, West Bengal, 731235, India
}

\begin{abstract}
The biological synthesis of nanoparticles using plant extracts plays an important role in the field of nanotechnology. In this study, rapid, simple approach was applied for synthesis of silver nanoparticles using Clerodendrum infortunatum, Mucuna interrupta, Phlogancanthus thyrsiflorus and Sansevieria trifasciata aqueous leaf extract. The plant extract acts both as reducing agent as well as capping agent. To identify the compounds responsible for reduction of silver ions, the functional groups present in plant extract were investigated by FTIR. Various techniques used to characterize synthesized nanoparticles are Scanning Electron Microscopy (SEM), Atomic Force Microscopy (AFM) and UV-Visible spectrophotometer. Results confirmed that this protocol was simple, rapid, one step, eco-friendly, non-toxic and might be an alternative conventional physical/chemical methods. Conversion of silver nanoparticles takes place at room temperature without the involvement of any hazardous chemicals.
\end{abstract}

Keywords: silver nanoparticles, UV-Vis spectra, non-timber forest products (NTFP), SEM, AFM, FTIR

\section{Introduction}

Nanotechnology is the science of materials which have at least one dimension in the range of 1-100 nm. Nanotechnology provides the facility to engineer the properties of materials by controlling their size, and this has conducted researches toward a multitude of potential uses for nanomaterials (Benjamin and Bharathwaj, 2011). Metallic nanoparticles exhibit unusual optical, thermal, chemical, and physical properties (Bains, 1993). The synthesis of inorganic nanoparticle through biological process makes more biocompatible and environmentally benign (Ahmed et al., 2016). Several techniques including chemical and physical method are developed to synthesise metallic nanoparticles. However, recently a resurgent developed for the green synthesis of several nanoparticles through biological mean (Thuesombat et al., 2014). The use of plant extract for the synthesis of nanoparticles it proves to be environment friendly and cost effective as compared to the physical or chemical procedures which are hazardous for the environment (Sant et al., 2013). There are several literature related to the synthesis of silver nanoparticle using plant extract, fungi, bacteria (Sastry et al., 1998; Sathishkuma et al., 2009; Dwivedi and Gopal, 2010; Philip, 2010; Kaviya, 2011; Ghosh et al., 2012).

Synthesis of inorganic nanoparticle through biological process is well known as "Green Technology" (Mittal et al.,
2014). A lot of interest has been created by the term "green nanotechnology" (Cao, 2004). In a broad sense, this term includes a wide range of possible applications, from nanotechnology enabled, environmentally friendly manufacturing processes that reduce waste products (ultimately leading to atomically precise molecular manufacturing with zero waste). It is well-known the use of nanomaterials as catalysts for greater efficiency in current manufacturing processes by minimizing or eliminating the use of toxic materials (green chemistry principles); (Mukherjee $e t$ al., 2005), the use of nanomaterials and nanodevices to reduce pollution (e.g. water and air filters); and the use of nanomaterials for more efficient alternative energy production (e.g. solar and fuel cells).

The silver nanoparticle act on a broad range of target sites both extracellularly as well intracellularly (Parashar et al., 2009). These nanoscale matters going to play important role in several technological areas such as: catalysis, optic, mechanic, magnetic and energy sciences (Govindaraju et al., 2009). Beside these nanomaterial have a variety of biomedical applications are also included in specific treatments in dermatological disease, in surgery for using nanorobots and other drug formulation application (Sandi and Sandi, 2004).

Non-timber forest products (NTFP) are becoming increasingly recognized by the public and in forest management planning (Ehlers et al., 2003). Each NTFP species possesses its 
own complex set of economic, ecological, and social aspects related to harvesting (Tedder et al., 2002). In the present study five ethno medicinal NTFP plants have used for isolation of silver nanoparticles.

\section{Materials and Methods}

\section{Preparation of plant extract}

Plant extract have been prepared from fresh leaves of Clerodendrum japonicum (Thunb.) Sweet, Clerodendrum infortunatum L., Mucuna interrupta Gagnep., Phlogancanthus thyrsiflorus Nees and Sansevieria trifasciata Prain. Leaves, weighing $25 \mathrm{~g}$ were thoroughly washed thrice in distilled water for $15 \mathrm{~min}$, dried, cut into fine pieces and were boiled in a $500 \mathrm{ml}$ Erlenmeyer flask with $100 \mathrm{ml}$ of sterile distilled water up to 5 $\mathrm{min}$ and were filtered.

\section{Synthesis of silvernanoparticles}

One $\mathrm{mM}$ aqueous solution of silver nitrate $\left(\mathrm{AgNO}_{3}\right)$ was prepared and used for the synthesis of silver nanoparticles. Ten $\mathrm{ml}$ of plant extract was added into $90 \mathrm{ml}$ of aqueous solution of 1 $\mathrm{mM}$ silver nitrate for reduction into $\mathrm{Ag}^{+}$ions and kept at room temperature for 24 hours in a dark place.

\section{UV-Visspectra analysis}

The reduction of pure $\mathrm{Ag}^{+}$ions was monitored by measuring the UV-Vis spectrum of the reaction medium at 5 hours after diluting a small aliquot of the sample into distilled water. The UV spectrum of the same sample was also taken after $24 \mathrm{hrs}$ incubation to note the complete bioreduction. UV-Vis spectral analysis was done by using UV-Vis spectrophotometer UV-2450 (Shimadzu).

\section{SEM analysis of silver nanoparticles}

Scanning Electron Microscopic (SEM) analysis was done using SEM (JSM- 6360, Joel) at SAIF, NEHU, Shillong (India). Thin films of the sample were prepared on a carbon coated copper grid by just dropping a very small amount of the sample on the grid; extra solution was removed using a blotting paper and then the film on the SEM grid were allowed to dry by putting it under a mercury lamp for $5 \mathrm{~min}$.

\section{AFM study}

For AFM (Atomic-force microscopy) study a thin film of the sample solution was prepared on a Bluestar coverslip, extra solution was removed using a blotting paper and then the film were allowed to dry at room temperature and further used for the AFM study.

\section{FTIR analysis of dried biomass after bio-reduction}

To remove any free biomass residue or compound that is not the capping ligand of the nanoparticles, the residual solution of $100 \mathrm{ml}$ after reaction was centrifuged at $5000 \mathrm{rpm}$ for $10 \mathrm{~min}$ and the resulting suspension was re-dispersed in $10 \mathrm{ml}$ sterile distilled water. The centrifuging and re-dispersing process was repeated three times. Thereafter, the purified suspension was freeze dried to obtain dried powder. Finally, the dried nanoparticles were analysed by FTIR Nicolet Avatar 660 (Nicolet, USA).

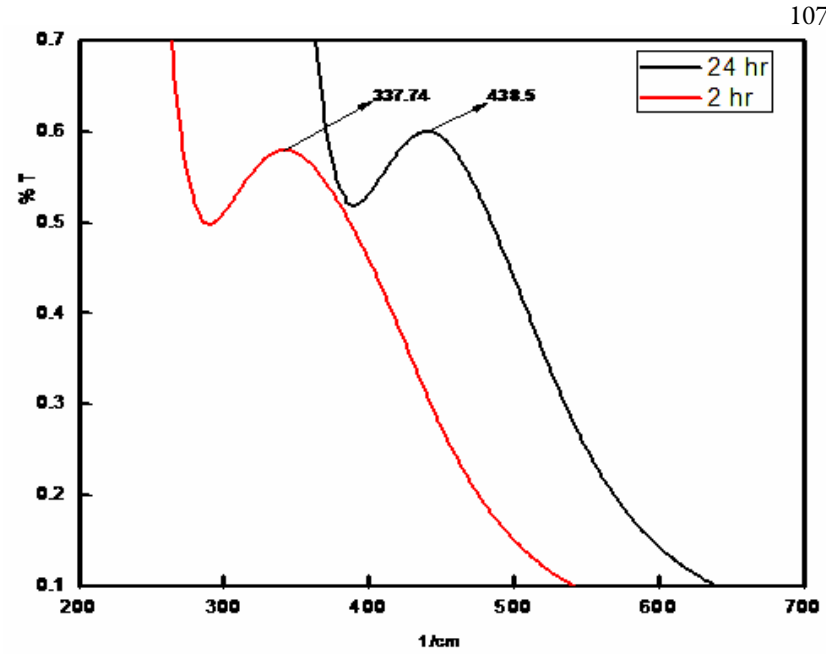

Fig. 1. Ultraviolet-visible spectra recorded as a purpose of reaction time of $\mathrm{AgNO}_{3}$ solution with Clerodendrum japonicum

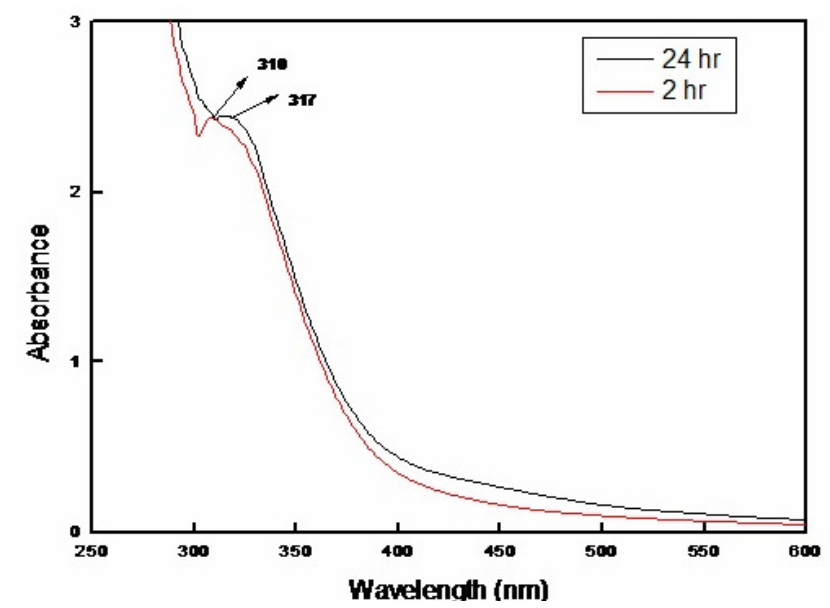

Fig. 2. Ultraviolet-visible spectra recorded as a purpose of reaction time of $\mathrm{AgNO}_{3}$ solution with Mucuna interrupta

\section{Results}

\section{UV-Vis spectral analysis}

Reduction of the silver ion on Ag nanoparticle during exposure of the plants extract could be followed by the optical change in colour. UV-Vis spectrograph of the colloidal solution of $\mathrm{Ag}$ nanoparticles has been recorded as a function of time (Figs. 1 and 2). The solution changes into deep brown to reddish brown colour due to bioreduction. It is well known that silver nanoparticles exhibit reddish brown in solution (Sastry et al., 1998). The change in colour arises due to excitation of surface plasmon vibration in the silver nanoparticles (Langmuir, 1996). However, absorption spectra of the Ag nanoparticles formed in the reaction mixture varies widely. Nanoparticle formation is dependent on different physical as well chemical factor such as metal ion concentration, incubation time, $\mathrm{pH}$ and temperature. Out of the five selected species for the present study Clerodendrum japonicum, Mucuna interrupta shows rapid bioreduction of $\mathrm{Ag}^{+}$within 1-2 hr. While, Clerodendrum infortunatum, Phlogancanthus thyrsiflorus and Sansevieria trifasciata requires longer time period (24hr.). 
108

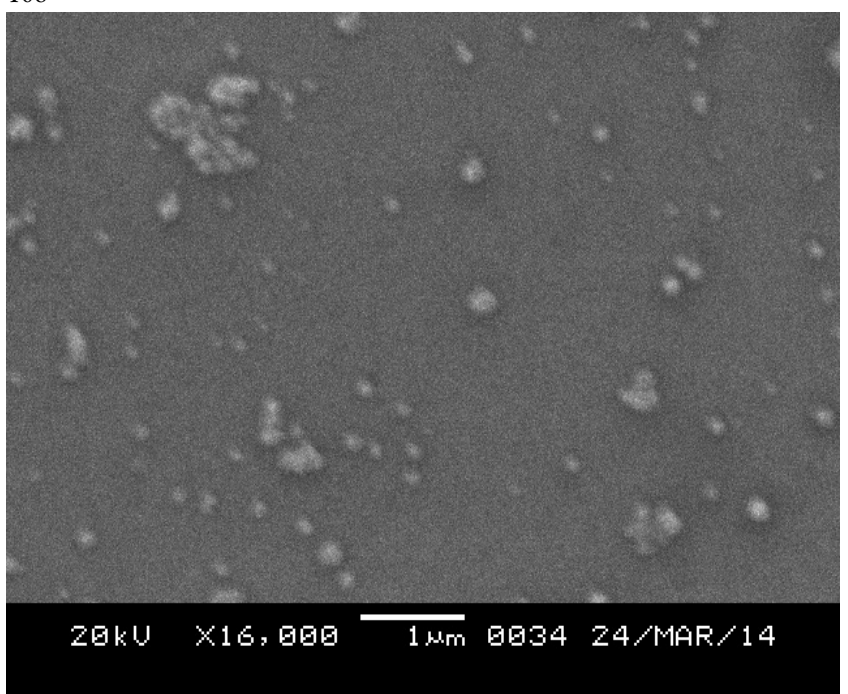

Fig. 3. SEM image of silver nanoparticles synthesized from Mucuna interrupta

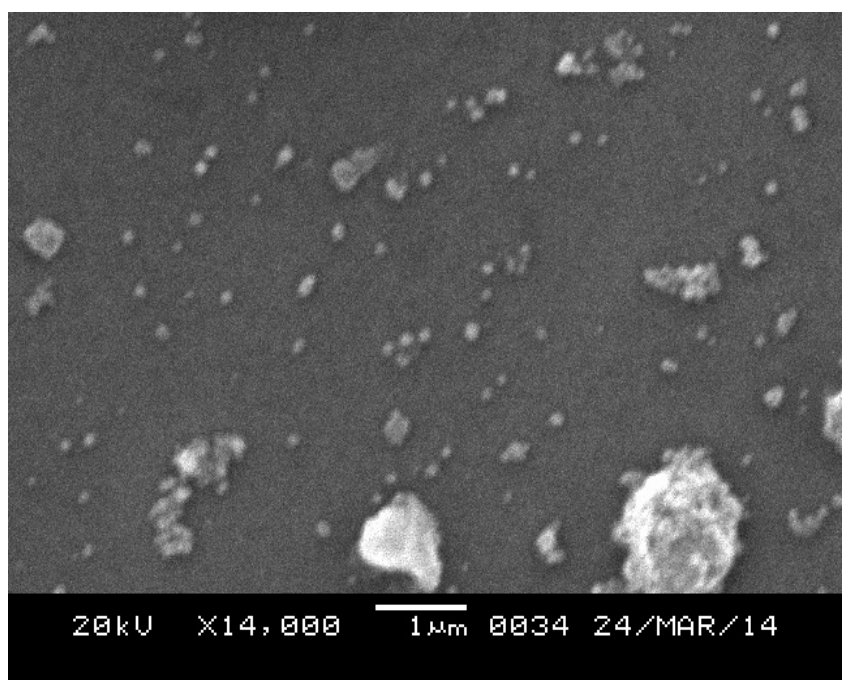

Fig. 4. SEM image of silver nanoparticles synthesized from Phlogancanthus thyrsiflorus

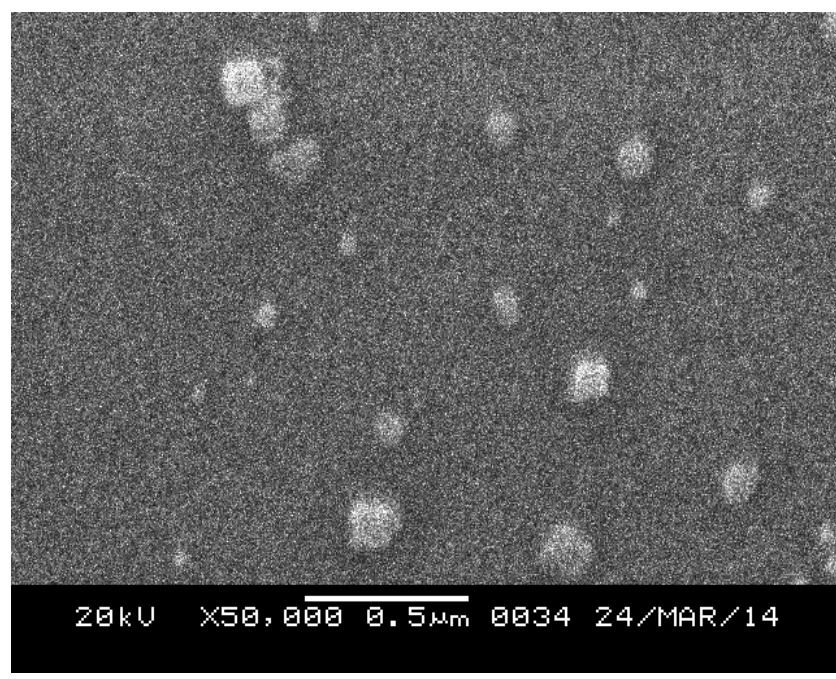

Fig. 5. SEM image of silver nanoparticles synthesized from Sansevieria trifasciata

\section{SEM analysis}

The Scanning Electron Microscope image shows that high density silver nanoparticles were formed by the Clerodendrum japonicum, Clerodendrum infortunatum, Mucuna interrupta, Phlogancanthus thyrsiflorus and Sansevieria trifasciata plant extract (Figs. 3, 4 and 5).

\section{AFM analysis}

AFM is a powerful tool to study the morphology of biofunctionalized particles. The bio-functionalization of AgNPs prepared by medicinal plant extract was further confirmed by AFM study. The three dimensional study of the biofunctionalized nanoparticles were made on tapping mode technique. From the AFM study (Figs. 6, 7, 8 and 9) can be predicted the shape of the nanoparticles that are nearly spherical with some irregular shaped particles and are randomly distributed. The size of the nanoparticles also varied greatly and might be depends on the plant source. In case of Clerodendrum japonicum the nanoparticles range from 26.49 to $54.28 \mathrm{~nm}$, in Clerodendrum infortunatum from 25.62 to $135 \mathrm{~nm}$, in Mucuna interrupta it was 37.89 to $82.14 \mathrm{~nm}$, in Phlogancanthus thyrsiflorus ranged from 20.27 to $52.36 \mathrm{~nm}$ and in Sansevieria trifasciata from 22.36 to $72.54 \mathrm{~nm}$.

\section{FTIR measurements}

FTIR measurements were carried out to identify the possible biomolecules accountable for the stabilization and for the reduction of the $\mathrm{Ag}^{+}$ions and the capping of the bioreduced silver nanoparticles synthesized by the broth. The representative spectra of stabilized silver nanoparticles obtained from Clerodendrum japonicum 3413.44, 2924.41, 2853.78,

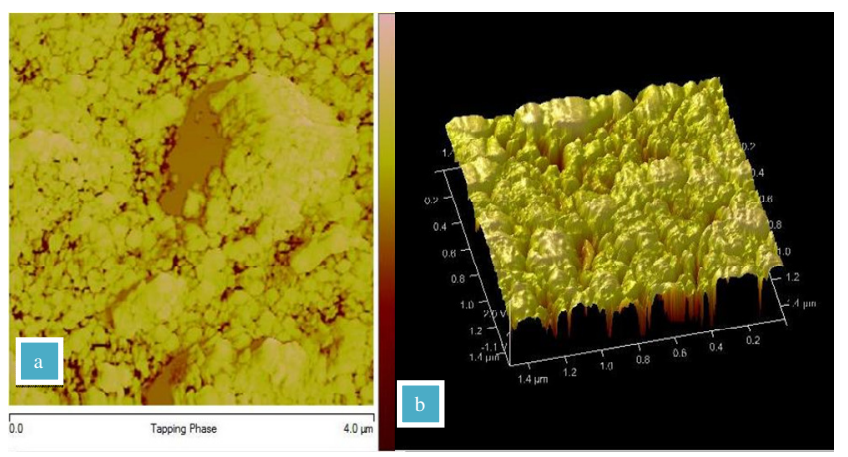

Fig. 6a. AFM study of silver nanoparticles synthesized using Clerodendrum japonicum leaves extract and 3D view (b)

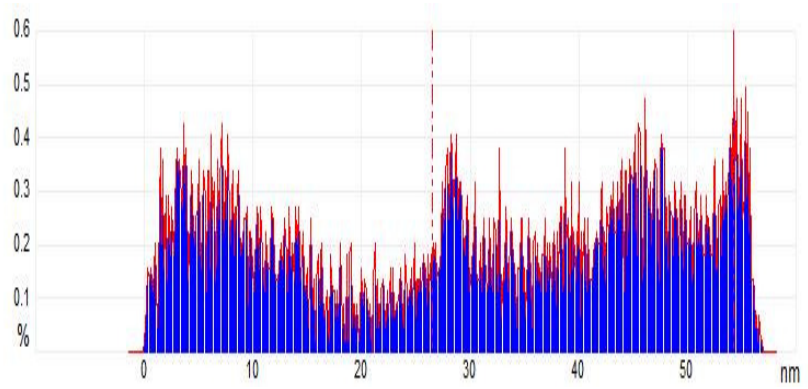

Fig. 6c. Topography of silver nanoparticles synthesized using Clerodendrum japonicum leaves extract showing distribution of size (26.49-54.28 nm) 


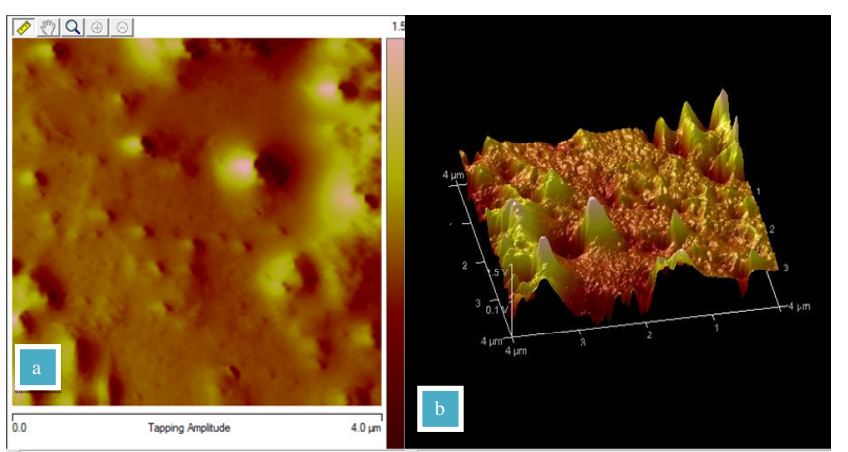

Fig.7a. AFM study of silver nanoparticles synthesized using Mucuna interrupta leaves extract and 3D view (b)

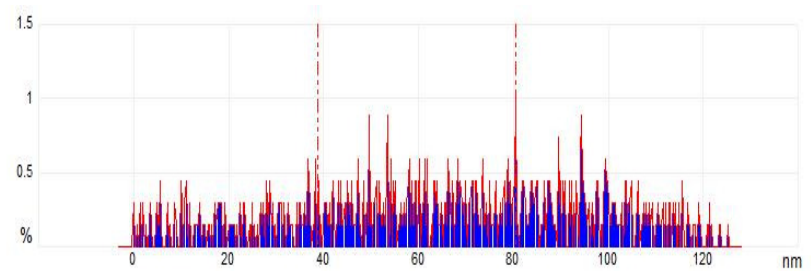

Fig.7c. Topography of silver nanoparticles synthesized using Mucuna interrupta leaves extract showing distribution of size (37.89-82.14 nm)

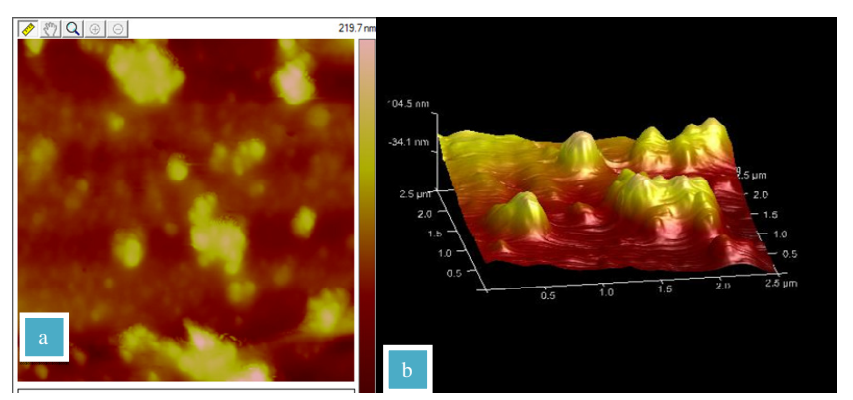

Fig. 8a. AFM study of silver nanoparticles synthesized using Phlogancanthus thyrsiflorus leaves extract and 3D view (b)

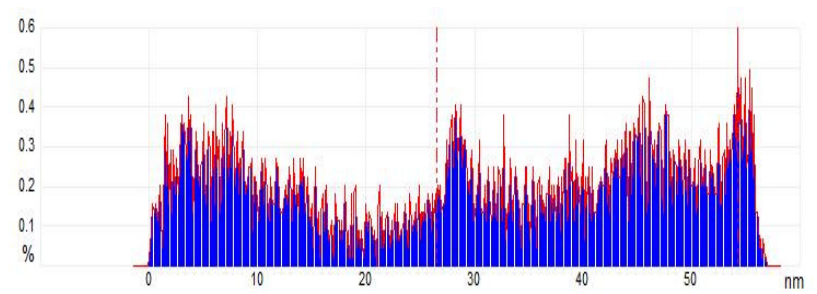

Fig. 8c. Topography of silver nanoparticles synthesized using Phlogancanthus thyrsiflorus leaves extract showing distribution of size $(20.27-52.36 \mathrm{~nm})$

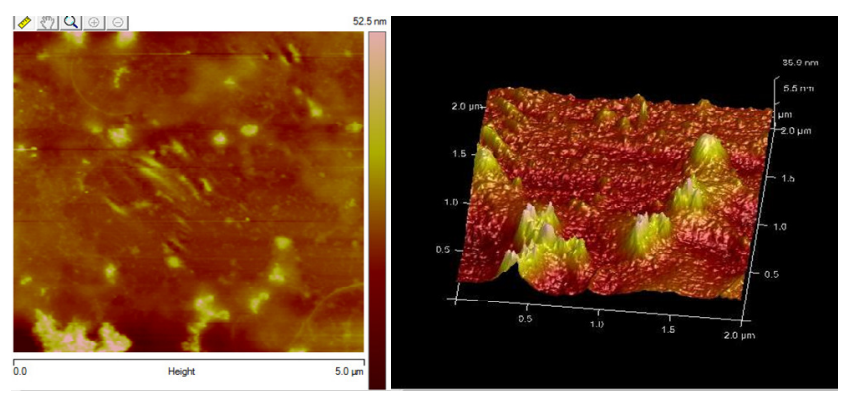

Fig. 9a. AFM study of silver nanoparticles synthesized using Sansevieria trifasciata leaves extract (left) and 3D view (right)

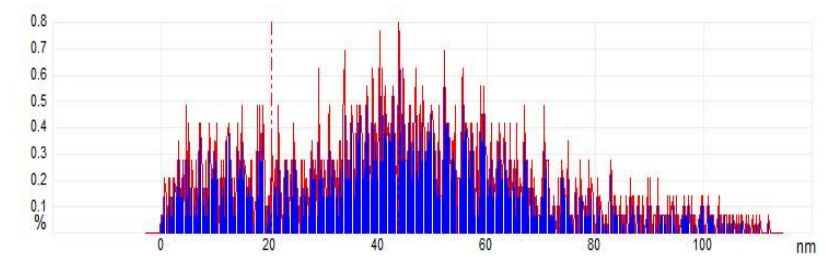

Fig. 9b. Topography of silver nanoparticles synthesized using Sansevieria trifasciata leaves extract showing distribution of size $(22.36-72.54 \mathrm{~nm})$

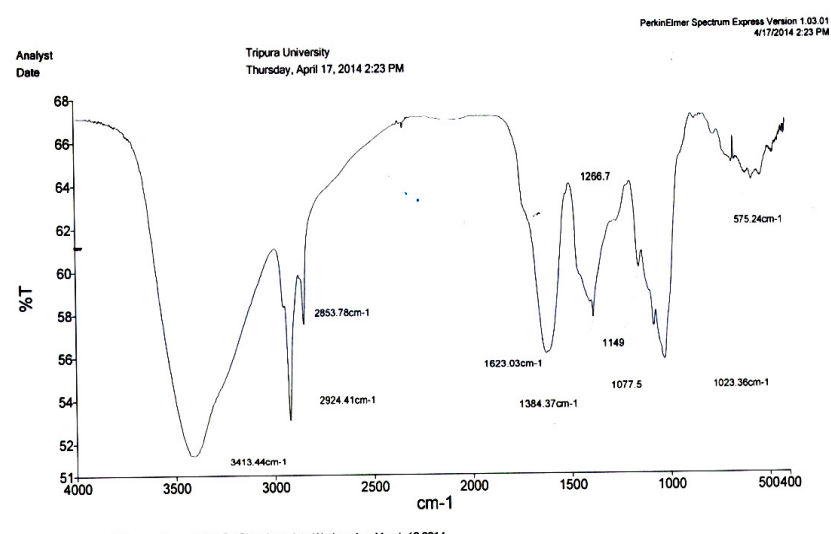

Fig. 10. FTIR spectra of Ag nanoparticles synthesized using Clerodendrum japonicum leaves extracts

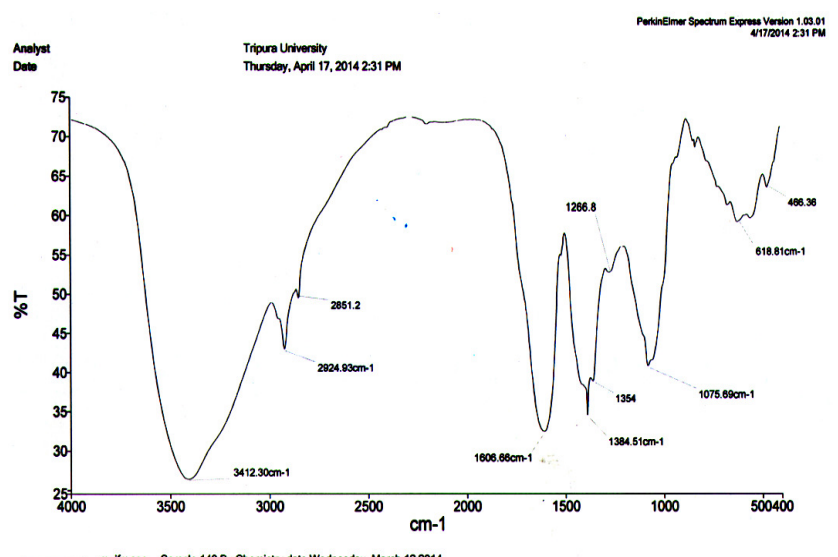

Fig. 11. FTIR spectra of Ag nanoparticles synthesized using Mucuna interrupta leaves extracts

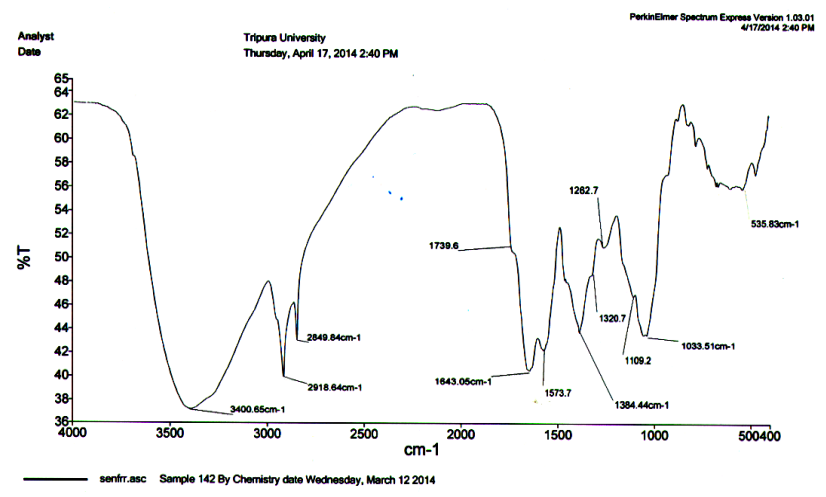

Fig. 12. FTIR spectra of $\mathrm{Ag}$ nanoparticles synthesized using Sansevieria trifasciata leaves extracts 
110

1623.03, while in Clerodendrum infortunatum show IR peaks at 3264.90, 2921.7, 2855.3, 2320.3,1627.18 etc. In case of Mucuna interrupta, Phlogancanthus thyrsiflorus and Sansevieria trifasciata the FTIR peaks are at 3412.30, 2924.93, 2851.2, $1606.663434 .74,2927.21,2851.2,1635.50$ and 3400.65, 2918.64, 2849.84, 1739.6, 1643.05 respectively (Figs. 10, 11 and 12).

\section{Discussion}

Earlier studies show it was a long-duration process when using some sources such as fungi which have $72 \mathrm{~h}$ duration for synthesizing the silver nanoparticles (Banu et al., 2011). Several other plants sources also have much longer time duration for silver ion reduction process (Vanaja et al., 2013).The nanoparticles were primarily characterized by UV-Vis spectroscopy, which was proved to be a very useful technique for the analysis of nanoparticles. In the UV spectrum, the broadening of the peak indicated that the particles are polydispersed. It is generally recognized that UV-Vis spectroscopy could be used to examine size and shape controlled nanoparticles in aqueous suspension (Wiley et al., 2006). The SNP's have free electrons, which gave rise to an SPR absorption band (Noginov et al., 2006), due to a combined vibration of electrons of metal nanoparticles in resonance with the light wave (Nath et al., 2007, Dubey et al., 2010). Due to the excitation of plasma resonance on interband transitions, some metallic nanoparticles dispersions exhibit unique bands/peaks (Creighton and Eadont, 1993). The position and shape of plasmon absorption of silver nanoclusters are strongly dependent on the particle size, dielectric constant of the medium and surface adsorbed species.

According to Mie's theory, only a single SPR band is expected in the absorption spectra of spherical nanoparticles, whereas anisotropic particles could give rise to two or more SPR bands depending on the shape of the particles. The number of SPR peaks increases as the symmetry of the nanoparticles decreases (Sosa et al., 2003). Thus, spherical nanoparticles, disks, and triangular nameplates of silver show one, two, and more peaks, respectively. The broadness of the peak is a good indicator of the size of the nanoparticles. As the particle size increases, the peak becomes narrower with a decreased bandwidth and increase band intensity (Kong and Jong, 2006). In the present study, the reaction mixtures showed a single SPR band revealing spherical shape of silver nanoparticles, which were further confirmed by SEM study. The SEM image of the nanoparticles synthesized by the ethno medicinally important plants of Tripura were assembled on to the surface due to the interaction such as hydrogen bond and electrostatic interactions between the bio-organic capping molecules bound to the $\mathrm{Ag}$ nanoparticles. The silver synthesised nanoparticles were not in direct contact even within the aggregates, indicating stabilization of the nanoparticles by a capping agent (Song and Kim, 2008).

he peaks at $3413.44,3264.90,3412.30,3434.74$ and $3400.65 \mathrm{~cm}^{-1}$ correspond to $\mathrm{O}-\mathrm{H}$ stretching generated from phenolic compound of the plants indicating their medicinal property (Wojdylo et al., 2007). The peaks at $1623.03 \mathrm{~cm}^{-1}$ of Clerodendrum japonicum, $1627.18 \mathrm{~cm}^{-1}$ in Clerodendrum infortunatum, $1606.66 \mathrm{~cm}^{-1}$ in Mucuna interrupta, 1635.50 $\mathrm{cm}^{-1}$ in Phlogancanthus thyrsiflorus and $1643.05 \mathrm{~cm}^{-1}$ in
Sansevieria trifasciata are assigned to the amide I bonds of proteins that may arise due to carboxyl stretch and $\mathrm{N}-\mathrm{H}$ deformation vibrations. Studies have confirmed the fact that the carbonyl group form amino acid residues and proteins has the stronger ability to bind metal indicating that the proteins could possibly form a layer covering the metal nanoparticles (capping of silver nanoparticles) to prevent agglomeration and thereby stabilize the medium (Kanchanaa et al., 2011).

In the present study the nanoparticles synthesized with different plant extracts varied in their absorption maxima $(\lambda \max )$. The different groups of biochemical compounds (polyphenols, flavonoids, sterols, triterpenes, triterpenoid saponins, beta-phenylethylamines, tetrahydroisoquinolines, reducing sugars like glucose and fructose, amino acids and proteins) present in plants possess free radical scavenging activities (Morones et al., 2005) which could be responsible for the reduction of silver and synthesis of nanoparticles through biogenic routes. The reduction of the metal ions and stabilization of silver nanoparticles is believed to occur by the terpenoid, flavonoid constituents of extract as well as by reducing sugar ascorbate and protein molecule in the broth (Palaniselvam et al., 2012)

\section{Acknowledgement}

This work was supported by the DBT Grant (Grant No: BCIL/NER-BPMC/2012/592) under DBT Twinning Project.

\section{References}

Ahmed, S, Saifullah, Ahmad M, Swami BL, Ikram S (2016). Green synthesis of silver nanoparticles using Azadirachta indica aqueous leaf extract. Journal of Radiation Research and Applied Science 9(1):1-7.

Bains W (1993). Biotechnology from A to Z. Oxford University Press.

Banu A, Rathod V, Ranganath E (2011). Silver nanoparticle production by Rhizopus stolonifer and its antibacterial activity against extended spectrum $\beta$-lactamase producing (ESBL) strains of enterobacteriaceae. Material Research Bulletin 46:1417-1423.

Benjamin G, Bharathwaj S (2011). Biological synthesis of silver nanoparticles from Allium cepa (onion) and estimating its antibacterial activity. International Conference on Bioscience, Biochemistry and Bioinformatics. IPCBEE 5:35-38. IACSIT Press, Singapore.

Ehlers T, MB Shannon, Mackinnon A (2003). Inventory of non timber forest product plant and fungal species in the Robson Valley. BC Journal of Ecosystem Management 4(2):1-15.

Cao G (2004). Nanostructures and nanomaterials: Synthesis, properties and applications. Imperial College Press, London.

Creighton JA, Eadont DG (1991). Ultraviolet-visible absorption spectra of the colloidal metallic elements. Journal of Chemical Society Faraday Trans 87:3881-3891.

Dubey SP, Lahtinenb M, Särkkäa H, Sillanpä M (2010). Bioprospective of Sorbus aucuparia leaf extract in development of silver and gold nanocolloids. Colloids and Surfaces B: Biointerfaces 80:26-33. 
Dwivedi AD, Gopal K (2010). Biosynthesis of silver and gold nanoparticles using Chenopodium album leaf extract. Colloids and Surfaces A 369(1-3):27-33.

Ghosh S, Patil S, Ahire M (2012). Synthesis of silver nanoparticles using Dioscorea bulbifera tuber extract and evaluation of its synergistic potential in combination with antimicrobial agents. International Journal of Nanomedicine 7:483-496.

Govindaraju K, Kiruthiga V, Ganesh KV, Singaravelu G (2009). Extracellular synthesis of silver nanoparticles by a marine alga, Sargassum wightii Grevilli and their antibacterial effects. Journal of Nanoscience and Nanotechnology 9:5497-5501.

Kanchanaa A, Agarwalb I, Sunkarc S, Nellored J, Namasivayamd K (2011). Biogenic silver nanoparticles from spinacia oleracea and lactuca sativa and their potential antimicrobial activity. Digest Journal of Nanomaterials and Biostructures 6(4):1741-1750.

Kaviya S, Santhanalakshmi J, Viswanathan B, Muthumary J, Srinivasan K (2011). Biosynthesis of silver nanoparticles using citrus sinensis peel extract and its antibacterial activity. Spectrochimica Acta Part A 79(3):594-598.

Kong H, Jang J (2006). One step fabrication of silver nanoparticles embedded polymer nanofibers by radical mediated dispersion polymerization. Chemical Community 3010-3012

Mittal, A, Batra A, Singh M, Sharma M (2014). Phytofabrications of nanoparticles through plants as nanofactors. Advances in Natural Sciences: Nanoscience and Nanotechnology. doi:10.1088/20436262/5/4/043002.

Morones JR, Elechiguerra JL, Camacho A, Holt K, Kouri JB, Ramfrez JT, Yacaman MJ (2005). The bactericidal effect of silver nanoparticles. Nanotechnology 16:23-46.

Nath SS, Chakdar D, Gope G (2007). Synthesis of CdS and ZnS quantum dots and their applications in electronics. Nanotrends 2(3):20-28.

Noginov MA, Zhu G, Bahoura M, Adegoke J, Small C, Ritzo BA, Drachev VP, Shalaev VM (2006). The effect of gain and absorption on surface plasmon in metal nanoparticles. Applied Physics B 86:458-460.

Palaniselvam K,Velangani AK, Govindam S (2012). Leaf assisted bioreduction of silver ions using leaves of Centella asiatica $L$ and its bioactivity. Journal of Life Science 1(1):46-49.

Parashar V, Parashar R, Sharma B, Pandey AC (2009). Parthenium leaf extract mediated synthesis of silver nanoparticles: a novel approach towards weed utilization. Digest Journal of Nanomaterials and Biostructures 4(1):45-50.
Philip D (2009). Biosynthesis of $\mathrm{Au}, \mathrm{Ag}$ and $\mathrm{Au}-\mathrm{Ag}$ nanoparticles using edible mushroom extract. Spectrochimica Acta Part A 73:374-381.

Sandi I, Sandi BS (2004). Silver Nanoparticles as antimicrobial agents, a case study on E-coli as a model for gram negative bacteria. Journal of Colloid and Interface Science 275:177-182.

Sant DG, Gujarathi TR, Harne SR, Ghosh S, Kitture R, Kale S, Chopade BA, Pardesi KR (2013). Adiantum philippense L. frond assisted rapid green synthesis of silver and gold nanoparticles. Journal of Nanoparticles doi.org/10.1155/2013/182320.

Sastry M, Patil V, Sainkar SR (1998). Electrostatically controlled diffusion of carboxylic acid derivatized silver colloidal particles in thermally evaporated fatty amine films. Journal of Physics and Chemistry B 102:1404-1409.

Sathishkumar M, Sneha K, Won SW, Cho CW, Kim S, Yun YS (2009). Cinnamon zeylanicum bark extract and powder mediated green synthesis of nano-crystalline silver particles and its bactericidal activity. Colloids and Surfaces B 73(2):332338.

Song JY, Kim B (2008). Rapid biological synthesis of silver nanoparticles using plant leaf extracts. Bioprocess Biosystem Engineering 32:79-84.

Sosa IO, Noguez C, Barrera RG (2003). Optical properties of metal nanoparticles with arbitrary shapes. Journal of Physics and Chemistry B 107:62-69.

Tedder S, D Mitchell, Hillyer A (2002). Property rights in the sustainable management of non-timber forest products. Economics and Trade Branch, B.C. Ministry of Forests, Victoria, B.C. Forest Renewal BC Report.

Thuesombat P, Hannongbua S, Akasit S, Chadchawan S (2014). Ecotoxicology and environmental safety effect of silver nanoparticles on rice (Oryza sativa L. cv. KDML 105) seed germination and seedling growth. Ecotoxicology and Environmental Safety 104:302-309.

Vanaja G, M Paulkumar G, Rajeshkumar K, Malarkodi CS, Annadurai G (2013). Photosynthesis of silver nanoparticles by Cissus quadrangularis: influence of physiochemical factors. Journal of Nanostructure in Chemistry 3(1):1-8.

Wiley BJ, Im SH, McLellan J, Seikkinen A, Xia Y (2006). Maneuvering the surface plasmon resonance of silver nanostructures through shape-controlled synthesis. Journal of Physical Chemistry B 110(32):15666-15675.

Wojdylo A, Oszmianski J, Czemerys B (2007). Antioxidant activity and phenolic compounds in 32 selected herbs. Food Chemistry 105:940-949. 